\title{
Arginine-Vasopressin Content of Hippocampus and Amygdala During Passive Avoidance Behavior in Rats
}

\author{
F. LACZI* ${ }^{*}$ O. GAFFORI, E. R. DE KLOET** and D. DE WIED \\ Rudolf Magnus Institute for Pharmacology, Medical Faculty, University of Utrecht, Vondellaan 6, 352I GD Utrecht, (The Netherlands)
}

(Accepted April 5th, 1983)

Key words: vasopressin - hippocampus - amygdala - behavior

Arginine-vasopressin (AVP) is involved in memory processes. The memory effects of AVP are mediated by neuronal mechanisms taking place in limbic-midbrain structures. Therefore, immunoreactive AVP (IR-AVP) was measured in hippocampus and amygdala of male Wistar rats during acquisition and retention of passive avoidance behavior.

IR-AVP concentration was decreased in the hippocampus immediately after the learning trial while IR-AVP content of the amygdala was not affected.

Animals that showed the passive avoidance response (good avoiders) at the $24 \mathrm{~h}$ or $120 \mathrm{~h}$ retention test had a reduced IR-AVP concentration in the hippocampus immediately after the test. However, IR-AVP content of the hippocampus was not different from that of non-shocked control animals when measured immediately before the $120 \mathrm{~h}$ retention test. Poor avoiders that showed only minor avoidance behavior did not differ in hippocampal IR-AVP content from non-shocked control animals. IR-AVP content of the amygdala was also not altered after the retention session.

These effects on IR-AVP content could only be shown in animals that were trained and habituated to the passive avoidance procedure. Such trained and habituated animals had an IR-AVP level in the hippocampus which did not differ from that of animals that were left undisturbed until sacrifice. When the animals were not trained, but placed for the first time in the passive avoidance apparatus without being exposed to the learning trial, the hippocampal IR-AVP content was reduced. Under these circumstances additional exposure to the electric footshock did not lead to a measurable further decrease in IR-AVP content of the hippocampus. Again, IR-AVP content of the amygdala was not affected. It is proposed that learning and retention of a passive avoidance response is associated with a reduction in hippocampal IR-AVP content. The reduction possibly reflects increased secretory activity at the peptidergic terminal. This AVP released at the terminal might be instrumental in facilitating memory formation

\section{INTRODUCTION}

Vasopressin (AVP) is involved in memory processes. Administration of AVP and related peptides increase resistance to extinction of active $e^{4,9.10}$ and passive avoidance behavior 1.4 and reverse or prevent experimental amnesia ${ }^{15,26}$, Intracerebroventricular (i.c.v.) administration of AVP induces similar effects, but in much lower doses than after peripheral administration ${ }^{11}$. Furthermore, i.c.v. but not intravenous injection of AVP antiserum immediately after the learning trial or prior to the retention test induces a marked deficit in passive avoidance performance ${ }^{29}$.

These observations indicate that centrally released AVP rather than AVP secreted into the peripheral circulation is physiologically involved in storage and retrieval processes. Subsequent studies showed that the level of immunoreactive AVP (IR-AVP) in the CSF was closely associated with passive avoidance learning and retention ${ }^{22.24}$. Studies on the site of action showed that limbic-midbrain structures are involved in the memory effects of the peptide 5.19.21.30.31. Extrahypothalamic projections of the AVP-containing neurons innervate these limbic-midbrain regions and may serve to transport AVP to its site of action on behavior ${ }^{7}, 12,13,14,17,18,27,28$.

Recently we found that during passive avoidance behavior the IR-AVP concentration in the hippocampal-septal area was decreased, while that in the central amygdaloid nucleus was increased ${ }^{23}$. Both re-

\footnotetext{
* On leave of absence from the Endocrine Unit and Research Laboratory, 1st Department of Medicine, University Medical School, Szeged, Hungary.

** To whom all correspondence should be addressed.
} 
gions are essential brain structures in the control of avoidance behavior ${ }^{5,31}$. The present study was designed to further explore alterations in IR-AVP content of these brain regions during passive avoidance learning and retention.

\section{MATERIALS AND METHODS}

Male rats of a Wistar strain weighing $\pm 150 \mathrm{~g}$ were used. They had free access to water and food. The animal house was illuminated from $06.00 \mathrm{~h}$ to 20.00 $h$. The animals were placed in single cages 2 days before the experiment. They were transported from the animal house to the experimental room $1 \mathrm{~h}$ before the experiment unless described otherwise. All observations were made between 13.00 and $17.00 \mathrm{~h}$.

The passive avoidance procedure was adopted from Ader et al.2. The experimental apparatus consisted of an illuminated platform attached to a dark compartment equipped with a grid floor. After habituation to the dark compartment $(2 \mathrm{~min})$ rats were placed on the platform and allowed to enter the dark compartment. Since rats prefer dark to light, they normally enter within $15 \mathrm{~s}$. On the next day, after 3 more trials (intertrial interval $5 \mathrm{~min}$ ), one group received an unavoidable footshock (with a duration of 3 s) through the grid floor of the dark compartment (learning trial). The shock intensity applied was 1.0 $\mathrm{mA}$. Rats were removed from the box $10 \mathrm{~s}$ after the termination of the shock. Passive avoidance latencies (retention test) were tested at different times after the learning trial; the rat was placed on the platform and the latency to enter the dark compartment was measured up to a maximum of $300 \mathrm{~s}$. Depending on the passive avoidance latencies during the retention test the rats were classified as poor avoiders (latency $<100$ s) or good avoiders (latency $>100 \mathrm{~s}$ ).

Four experiments were performed. In the first experiment IR-AVP content of hippocampus and amygdala was measured in animals that were left undisturbed until sacrifice, subjected to ether anesthesia (45 s) or exposed to the experimental conditions of the passive avoidance procedure without prior habituation (for further details see Results). The second experiment concerned the IR-AVP response in rats sacrificed immediately after exposure to the 1.0 $\mathrm{mA}$ electric shock (learning trial) and in the third experiment animals were sacrificed immediately after the $24 \mathrm{~h}$ retention session. In the fourth experiment rats were sacrificed either immediately before or after the $120 \mathrm{~h}$ retention test. All shocked animals were compared with non-shocked controls and in some experiments sacrifice of the animals was preceded by ether anesthesia. Sacrifice occurred between 13.00 and $16.00 \mathrm{~h}$.

In order to investigate the IR-AVP content in certain brain regions the animals were decapitated, the skull was opened and the brain removed. The hippocampus was dissected ${ }^{16}$. Moreover, in two series of experiments the amygdala + overlying pyriform cortex was also dissected ${ }^{16}$. Tissues were homogenized in $1.0 \mathrm{ml}$ ice-cold $1.0 \mathrm{~N} \mathrm{HCl}$ by ultrasound homogenizer at $20 \mathrm{kcounts} / \mathrm{s}$ for $30 \mathrm{~s}$. Subsequently $1.0 \mathrm{ml}$ of buffer containing $67 \mathrm{mM} \mathrm{Na}_{2} \mathrm{HPO}_{4}$ and $67 \mathrm{mM}$ $\mathrm{KH}_{2} \mathrm{PO}_{4}$ was added. The $\mathrm{pH}$ was adjusted to 4.0 with $1.0 \mathrm{~N} \mathrm{NaOH}$. A $100 \mu \mathrm{l}$ aliquot of the homogenate was kept for determination of the protein content ${ }^{25}$. The remainder was centrifuged at $4{ }^{\circ} \mathrm{C}$ at $9000 \mathrm{rpm}$ for 10 $\mathrm{min}$. One $\mathrm{ml}$ of the supernates was used for the extraction of AVP using activated Vycor glass powder (20 $\mathrm{mg} / \mathrm{sample}$ ). The details of the extraction were reported elsewhere ${ }^{12,23,24}$.

After the extraction the evaporated residues were redissolved in $125 \mu$ l of RIA-assay buffer. Two samples of $50 \mu$ were taken from these solutions to determine the amount of IR-AVP. AVP determinations were performed in duplicate using a specific RIA system. The details of the assay procedure have been described elsewhere ${ }^{12,23}$. The antiserum used was highly specific for AVP, the cross-reactivity with oxytocin being less than $0.1 \%$, and with arginine-vasotocin $0.25 \%$. Synthetic AVP (pressor activity: 508 IU/mg, Organon, Oss, The Netherlands) was used as a standard, and for preparation of the tracer. The limit of detection of the RIA was $0.5 \mathrm{pg}$ AVP/assay tube. $10-50 \mathrm{pg} A V P$ and $1-5 \mathrm{mg}$ protein were present per assay tube. Recovery of AVP from Vycor extraction is about $70 \%$. RIA data were calculated on a Hewlett Packard 104 calculator, which was equipped with a logit curve fitting program. AVP levels were expressed in $\mathrm{pg} / \mathrm{mg}$ protein.

\section{Statistical analysis}

The data of each experiment were first analyzed with a Kruskal-Wallis test and subsequently a Mann-Whitney U-test. A probability level of less 


\section{TABLE I}

\section{Effect of various experimental conditions on the immunoreactive vasopressin (IR-AVP) content of hippocampus}

Group 1 was left undisturbed in the animal house until sacrifice. Group 2 were animals handled the day before and exposed to ether for $45 \mathrm{~s}$ prior to sacrifice or not. Group 3 were animals not handled and sacrificed immediately after exposure to $1.00 \mathrm{~mA}$ electric footshock or to no footshock $(0.00 \mathrm{~mA})$. Data are expressed in pg IR-AVP/mg protein. Values are given as median with, in lower brackets, the highest and lowest IR-AVP content.

\begin{tabular}{|c|c|c|c|c|}
\hline Group 1 & Group 2 & & Group 3 & \\
\hline Naive & Handled & & Not handle & \\
\hline controls & $\begin{array}{l}\text { Without } \\
\text { ether }\end{array}$ & $\begin{array}{l}\text { With } \\
\text { ether }\end{array}$ & $\begin{array}{l}0.00 \\
m A\end{array}$ & $\begin{array}{l}1.00 \\
m A\end{array}$ \\
\hline $\begin{array}{l}11.0(5)^{* *} \\
(8.1-17.6)\end{array}$ & $\begin{array}{l}12.6(7) \\
(5.7-23.3)\end{array}$ & $\begin{array}{l}12.0(8) \\
(7.5-19.0)\end{array}$ & $\begin{array}{l}5.8^{*}(12) \\
(3.1-16.5)\end{array}$ & $\begin{array}{l}5.7^{*}(12) \\
(1.8-22.0)\end{array}$ \\
\hline
\end{tabular}

* Different from naive control group ( $P<0.05$; Mann-Whitney U-test).

** Number of animals.

than 0.05 was accepted as a significant difference.

\section{RESULTS}

Five experimental conditions were used in the first experiment. One group of rats (naive controls) (5 animals per cage) was left undisturbed until decapitation. These 'naive' animals were decapitated in the animal house. The rats of a second group were placed each in single cages 2 days before decapitation and handled the day before sacrifice. Immediately prior to sacrifice 8 rats were anesthetized by exposure to ether for a strictly controlled period of $45 \mathrm{~s}$ and subsequently decapitated, while the other 7 rats were not subjected to ether anesthesia. A third group of 25 rats were each placed in single cages 2 days before decapitation and were studied after being exposed to the passive avoidance apparatus for the first time. Twelve of these animals were put on the platform of the experimental apparatus used for passive avoidance behavior, allowed to enter the dark compartment and subsequently decapitated. The other 13 rats were subjected to a footshock of high intensity (1.00 mA) and decapitated immediately thereafter.

IR-AVP content of hippocampus of handled animals was not different from those of naive controls (Table I). IR-AVP content of hippocampus of animals that were exposed for the first time to the passive avoidance apparatus was significantly lower than that of naive controls whether subjected to shock $(1.00 \mathrm{~mA})$ or not (Table I). Ether anesthesia for $45 \mathrm{~s}$ had no additional influence on IR-AVP levels in hippocampus.
In the second experiment IR-AVP content of hippocampus and amygdala was investigated immediately after the learning trial. Groups of rats habituated to the experimental condition of the passive avoidance procedure received either no shock or a $1.00 \mathrm{~mA}$ shock during the learning trial. IR-AVP content in hippocampus of shocked rats was significantly lower than that of non-shocked animals (Table II). This was not found in the amygdala.

In the third experiment IR-AVP content immediately after the $24 \mathrm{~h}$ retention test of hippocampus was studied. Groups of rats received no shock or a 1.00 $\mathrm{mA}$ shock during the learning trial. Animals were either anesthetized with ether for a strictly controlled

\section{TABLE II}

Immunoreactive vasopressin (IR-AVP) content in hippocampus and amygdala of rats subjected to passive avoidance behavior

Groups of male Wistar rats received either no shock $(0.00 \mathrm{~mA})$ or a $1.00 \mathrm{~mA}$ shock during the learning trial. Animals were decapitated immediately after the learning trial. Data are expressed in $\mathrm{pg}$ IR-AVP/mg protein. Values are given as median with, in lower brackets, the highest and lowest IR-AVP content.

\begin{tabular}{lll}
\hline $\begin{array}{l}\text { Shock intensity } \\
(m A)\end{array}$ & Hippocampus & Amygdala \\
\hline 0.00 & $13.4(12)^{* *}$ & $13.7(8)$ \\
& $(2.9->32.2)$ & $(1.1-39.2)$ \\
& & \\
1.00 & $6.2^{*}(13)$ & $17.6(7)$ \\
& $(2.8-10)$ & $(6.5-63.4)$
\end{tabular}

* Different from non-shocked $(0.00 \mathrm{~mA})$ group $(P<0.05$; Mann-Whitney U-test)

** Number of animals. 


\section{TABLE III}

Immunoreactive vasopressin (IR-AVP) content in hippocampus of rats subjected to passive avoidance behavior

Groups of rats received either no shock $(0.00 \mathrm{~mA})$ or a $1.00 \mathrm{~mA}$ shock during the learning trial. Animals were decapitated. Immediately after the $24 \mathrm{~h}$ retention test and prior to sacrifice either anesthetized with ether for $45 \mathrm{~s}$ (B) or not (A). Data are expressed in pg IR-AVP/mg protein. Values are given as median with, in lower brackets, the highest and the lowest IR-AVP content (upper panel), or in s latency (lower panel) with the 25 th and 75 th percentile in brackets.

\begin{tabular}{cll}
\hline & $A$ & $B$ \\
\hline IR-AVP (pg/mg protein) & & \\
$0.00 \mathrm{~mA}$ & $12.8(16)$ & $9.9(16)$ \\
& $(3.1-29.4)$ & $(3.6-18.0)$ \\
good avoiders & $6.5^{* \S}(11)$ & $4.8^{*}(10)$ \\
& $(5.2-12.3)$ & $(2.8-9.3)$ \\
poor avoiders & $13.4(5)$ & $7.9(6)$ \\
& $(8.5-15.6)$ & $(4.0-10.1)$ \\
Latency (s) & & \\
$0.00 \mathrm{~mA}$ & $3(16)$ & $2(16)$ \\
& $(2-4)$ & $(1-4)$ \\
good avoiders & $300^{* * *}(11)$ & $300^{* * *}(10)$ \\
& $(180-300)$ & $(300-300)$ \\
poor avoiders & $60^{* *}(5)$ & $15^{* *}(6)$ \\
& $(5-66)$ & $(4-71)$
\end{tabular}

* Different from non-shocked $(0.00 \mathrm{~mA})$ group $\left({ }^{*} P<0.05\right.$, ${ }^{* *} P<0.01,{ }^{* * *} P<0.001$, Mann-Whitney U-test).

$\$$ Different from poor avoiders $(\$ P<0.005)$.

period of time (45 s) before decapitation (B) or not (A).

The shocked rats displayed a significantly increased passive avoidance response at the $24 \mathrm{~h}$ retention test. Based on a $100 \mathrm{~s}$ latency criterion animals were divided into good and poor avoiders ${ }^{20}$. Good avoiders had a significantly lower IR-AVP concentration in hippocampus (Table III).

In the fourth experiment IR-AVP content of hippocampus and amygdala was measured at 5 days after the learning trial. Animals were either decapitated immediately before (B) or after (A) the $120 \mathrm{~h}$ retention test. The median value of the $120 \mathrm{~h}$ latency scores of the good avoiders was $285 \mathrm{~s}$ (Table IV).

As was the case after the $24 \mathrm{~h}$ retention test, the IR-AVP content of hippocampus of good avoiders was significantly lower than that found in the nonshocked animals. This content in all avoiders (good + poor avoiders) did not differ from non-shocked anjmals. No change in IR-AVP levels of hippocampus or amygdala was found in shocked rats decapitated immediately before the $120 \mathrm{~h}$ retention test.
TABLE IV

Immunoreactive vasopressin (IR-AVP) content in hippocampus and amygdala of rats subjected to passive avoidance behavior

Group of male Wistar rats received either no shock $(0.00 \mathrm{~mA})$ or a $1.00 \mathrm{~mA}$ shock during the learning trial. Animals were decapitated immediately after the $120 \mathrm{~h}$ retention test (A) or immediately before (B). Data are expressed in pg IR-AVP/mg protein. Values are given as median with, in lower brackets, the highest and the lowest IR-AVP content (upper panel), or in s latency (lower panel) with 25 th and 75 th percentile in brackets.

\begin{tabular}{lll}
\hline & Hippocampus & Amygdala \\
\hline IR-AVP (pg/mg protein) & & \\
(A) $0.00 \mathrm{~mA}$ & $11.0(8)$ & $17.4(8)$ \\
& $(6.8->39.3)$ & $(4.6->31.4)$ \\
(A) good avoiders & $6.8^{*}(5)$ & $24.2(5)$ \\
& $(6.0-10.1)$ & $(10.7->30.4)$ \\
(A) all avoiders & $8.0(8)$ & $18.1(8)$ \\
& $(6.0-11.3)$ & $(6.3->30.4)$ \\
(B) $0.00 \mathrm{~mA}$ & $10.4(8)$ & $18.9(8)$ \\
& $(6.0-16.5)$ & $(10.1-31.6)$ \\
(B) $1.00 \mathrm{~mA}$ & $10.7(8)$ & $22.7(8)$ \\
& $(10.7->30.4)$ & $(18.4->30)$
\end{tabular}

Latency (s)

$\begin{array}{ll}\text { (A) } 0.00 \mathrm{~mA} & 3(8) \\ & (2-5) \\ \text { (A) good avoiders } & 285(5)^{* * *} \\ & (186-300) \\ & 235(8)^{* * *} \\ \text { (A) all avoiders } & (15-292)\end{array}$

(B) $0.00 \mathrm{~mA}$

(B) $1.00 \mathrm{~mA}$

${ }^{*}$ Different from non-shocked $(0.00 \mathrm{~mA})$ group. ${ }^{*} P<0.05$; ${ }^{* *} P<0.01 ;{ }^{* * *} P<0.001$, Mann-Whitney U-test.

\section{DISCUSSION}

The present study demonstrated that the IR-AVP content of the hippocampus is related to the behavioral performance of rats in a one-trial learning passive avoidance task. Hippocampal IR-AVP content was decreased in good avoiders immediately after the retention test at $24 \mathrm{~h}$ as well as $120 \mathrm{~h}$ after the learning trial. Poor avoiders did not differ from nonshocked control animals in this respect.

This observation extends previous findings on IRAVP content of various brain regions during passive avoidance behavior. It was found that immediately after the $24 \mathrm{~h}$ retention test IR-AVP level was decreased in the paraventricular, suprachiasmatic and lateral septal nucleus, but increased in the central amygdaloid nucleus, locus coeruleus and subfornical 
organ. IR-AVP in the amygdala as dissected in this study (amygdala + overlying pyriform cortex) was not changed, possibly since the much larger tissue fragment masked the increase in IR-AVP in the small central amygdaloid nucleus as had been found previously 23 .

A reduced IR-AVP content was observed immediately after exposure to electric footshock during the learning trial in the hippocampus but not in the amygdala + pyriform cortex region. The decrease in hippocampal IR-AVP content was transient and not observed 5 days after the learning trial when measured immediately before the retention test. Naturally, the groups of rats that were sacrificed prior to the retention test contained animals that are potentially good or poor avoiders. However, immediately after the 5 day retention test 'good avoiders' displayed a depletion in hippocampal IR-AVP content. Thus, the reduction in IR-AVP content seems a consequence associated with memory of the aversive experience to which the animal had been exposed previously.

In fact, exposure of the animal to the test situation for the first time already provided a stimulus of sufficient potency to reduce hippocampal IR-AVP content. This was not found in animals trained and habituated the day before exposure to the passive avoidance apparatus. The decrease was of the same magnitude as that induced by the electric footshock. However, not every stimulus which is considered stressful resulted in a decreased IR-AVP content since exposure to ether anesthesia for $45 \mathrm{~s}$ failed to affect hippocampal IR-AVP content. It is of interest that, after $48 \mathrm{~h}$ water deprivation of rats, a reduced IR-AVP content was found in certain limbic regions (lateral and medial septum) while an increase was noted in the medial amygdaloid nucleus ${ }^{14}$. Unfortunately, there were no data provided for the hippocampus. That study14, however, also demonstrated that regulation of central IR-AVP content may be different in various brain regions.

The decreased hippocampal IR-AVP content after the retention trial may be due to an enhanced release of the peptide. Previous work from this laboratory showed that the IR-AVP level in the CSF increases immediately after the learning trial and at the $120 \mathrm{~h}$ retention test ${ }^{24}$. This increase in CSF depended on the intensity of the electric footshock experienced during the learning trial possibly as a result of an en- hanced IR-AVP release from nerve terminals. The immunoreactive material assayed in CSF and brain tissue was immunologically indistinguishable from synthetic AVP23.24. It cannot be excluded, however, that fragments of AVP are detected as well. A distinct AVP-immunoreactive peptide is present in extrahypothalamic tissues, that does not coelute with AVP after HPLC fractionation ${ }^{14}$. Such peptides could be generated from AVP by proteolytic enzymes known to be associated with synaptosomal plasma membranes 6 .

It has been attempted to relate neurochemical events to performance of rats in passive avoidance behavior. It was found that $\alpha$-methyl- $p$-tyrosine-induced noradrenaline disappearance was higher in the hippocampal dentate gyrus and that the dopamine disappearance was higher in the central amygdaloid of animals classified as good avoiders ${ }^{20}$. These indices suggest different turnovers of catecholamines in dorsal hippocampus and the amygdala in relation to behavioral performance. In another study it was found that the number of corticosterone receptors was about $20 \%$ higher in the hippocampus of good avoiders than that of poor avoiders ${ }^{3}$. Catecholamine turnover and number of steroid receptors were measured several days after the actual behavioral experiment. Both neurochemical parameters have been shown to be implicated in learning and memory processes 5,8 . The correlation of these parameters in the particular brain regions with behavioral performance is striking. However, there is an important difference with the findings on IR-AVP in the present study. The catecholamine turnover and steroid receptor number measured at a time not associated with the behavior suggest that these parameters represent inborn differences. Based on such innate differences, the change in IR-AVP content as reported in this study may measure the immediate response to a fearful situation. As such the IR-AVP response in limbic structures appears to be an extremely sensitive index for behavioral performance.

AVP released from nerve terminals could be instrumental in consolidation and retrieval of memory processes. The hippocampus and amygdala are highly sensitive to microinjections of AVP. Application of AVP in the dorsal hippocampus facilitates the consolidation of memory processes ${ }^{5.19}$, while local administration in the amygdala possibly involves neural 
mechanisms related to the retrieval type of action of AVP5.19. It is proposed that learning and retention of a passive avoidance response is associated with a reduction in hippocampal IR-AVP content. The reduction possibly reflects increased secretory activity at the peptidergic terminal. This AVP released at the terminal might be instrumental in facilitating memory formation.

\section{REFERENCES}

1 Ader, R. and De Wied, D., Effects of lysine-vasopressin on passive avoidance learning, Psychon. Sci., 29 (1972) 46-48.

2 Ader, R., Weijnen, J. A. W. M. and Moleman, P., Retention of a passive avoidance response as a function of the intensity and duration of electric shock, Psychon. Sci., 26 (1972) 125-128.

3 Angelucci, L., Valeri, P., Grossi, E., Veldhuis, H. D., Bohus, B. and De Kloet, E. R., Involvement of hippocampal corticosterone receptors in behavioral phenomena. In F. Brambilla, G. Racagni and D. de Wied (Eds.), Progress in Psychoneuroendocrinology, Elsevier, Amsterdam 1981, pp. 177-185.

4 Bohus, B., Ader, R. and De Wied, D., Effects of vasopressin on active and passive avoidance behavior, Horm. Behav., 3 (1972) 191-197.

5 Bohus, B., Conti, L., Kovács, G. L. and Versteeg, D. H. G., Modulation of memory processes by neuropeptides: interaction with neurotransmitter systems. In $\mathrm{C}$. Ajmone Marsan and H. Matthies (Eds.), Neural Plasticity and Memory Formation, Raven Press, New York, 1982, pp. $75-86$.

6 Burbach J. P. H., De Kloet, E. R. and De Wied, D., Oxytocin biotransformation in rat limbic brain: characterization of peptidase activities and significance in the formation of oxytocin fragments, Brain Research, 202 (1980) 401-414.

7 Buijs, R. M., Intra- and extrahypothalamic vasopressin and oxytocin pathways in the rat, Cell Tiss. Res., 192 (1978) 423-435.

8 De Kloet, E. R. and Veldhuis, H. D., Adrenocortical hormone action on the brain. In A. Lajtha (Ed.), Handbook of Neurochemistry Vol. VIII, Plenum, New York, in press.

9 De Wied, D., The influence of the posterior and intermediate lobe of the pituitary and pituitary peptides on the maintenance of a conditioned avoidance response in rats, Int. J. Neuropharmacol., 4 (1965) 157-167.

10 De Wied, D., Long term effect of vasopressin on the maintenance of a conditioned avoidance response in rats, Nature (Lond.), 323 (1971) 58-60.

11 De Wied, D., Behavioral effects of intracerebroventricularly administered vasopressin and vasopressin fragments, Life Sci., 19 (1976) 685-690.

12 Dogterom, J., Van Wimersma Greidanus, Tj. B. and De Wied, D., Vasopressin in cerebrospinal fluid and plasma of man, dog and rat, Amer. J. Physiol., 234 (1978) E463-E467.

13 Dorsa, D. M. and Bottemiller, L. A., Age-related changes of vasopressin content of microdissected areas of the rat brain, Brain Research, 242 (1982) 151-156.

14 Dorsa, D. M. and Bottemiller, L. A., Vasopressin-like pep-

\section{ACKNOWLEDGEMENT}

This study was supported by the Stichting Pharmacologisch Studiefonds.

tides in the rat brain: immunologic and chromatographic behavior and their response to water deprivation, Regulat. Peptides, in press.

15 Flexner, L. B., Flexner, J. B. and Roberts, R. B., Memory in mice analyzed with antibiotics, Science, 155 (1967) 1377-1383.

16 Gispen, W. H., Schotman, P. and De Kloet, E. R., Brain RNA and hypophysectomy: a topographical study, $\mathrm{Neu}$ roendocrinology, 9 (1972) 285-296.

17 Glick, S. and Brownstein, M. J., Vasopressin content of rat brain, Life Sci., 27 (1980) 1103-1110

18 Hoorneman, E. M. D. and Buijs, R. M., Vasopressin fiber pathways in the rat brain following suprachiasmatic nucleus lesioning, Brain Research, 243 (1982) 235-241.

19 Kovács, G. L., Bohus, B., Versteeg, D. H. G., De Kloet, E. R. and De Wied, D., Effect of oxytocin and vasopressin on memory consolidation: sites of action and catecholaminergic correlates after local microinjection into limbic-midbrain structures, Brain Research, 175 (1979) 303-314.

20 Kovács, G. L., Versteeg, D. H. G., De Kloet, E. R. and Bohus, B., Passive avoidance performance correlates with catecholamine turnover in discrete limbic brain regions, Life Sci., 28 (1981) 1109-1116.

21 Kovács, G. L., Buijs, R. M., Bohus, B. and Van Wimersma Greidanus, $\mathrm{Tj}$. B., Microinjection of arginine ${ }^{8}$-vasopressin antiserum into the dorsal hippocampus attenuates passive avoidance behavior in rats, Physiol. Behav., 28 (1982) 45-48.

22 Láczi, F., Fekete, M. and De Wied, D., Antidiuretic activity and immunoreactive arginin-vasopressin levels in eye plexus blood during passive avoidance behavior in rats, Life Sci., 32 (1983) 577-589.

23 Láczi, F., Gaffori, O., De Kloet, E. R. and De Wied, D., Differential regulation in immunoreactive arginine-vasopressin content of microdissected brain regions during passive avoidance behavior, Brain Research, 260 (1983) 342-346.

24 Láczi, F., Mens, W. B. J., Gaffori, O., Fekete, M. and De Wied, D., Arginine-vasopressin levels in cerebrospinal fluid during passive avoidance behavior in rats, Brain $R e$ search, submitted.

25 Lowry, O. H., Rosebrough, N. J., Farr, A. L. and Randall, R. J., Protein measurement with the Folin phenol reagent, J. biol. Chem., 193 (1951) 265-275.

26 Rigter, H., Van Riezen, H. and De Wied, D., The effect of $\mathrm{ACTH}$ and vasopressin analogues on $\mathrm{CO}$,-induced retrograde amnesia in rats, Physiol. Behav., 13 (1974) 381-388.

27 Sterba, G., Ascending neurosecretory pathways of the peptidergic type. In F. Knowles and L. Vollrath (Eds.), Neurosecretion: The Final Neuroendocrine Pathway, Springer, Berlin, 1974, pp. 38-47. 
28 Swanson, L. W., Immunohistochemical evidence for a neurophysin-containing autonomic pathway arising in the paraventricular $\mathrm{n}$. of the hypothalamus, Brain Research, 128 (1977) 346-353.

29 Van Wimersma Greidanus, Tj. B., Dogterom, J. and De Wied, D., Intracerebroventricular administration of antivasopressin serum inhibits memory consolidation in rats, Life Sci., 16 (1975) 637-644.

30 Van Wimersma Greidanus, Tj. B., Croiset, B. G., Bakker,
E. and Bouman, H., Amygdaloid lesions block the effect of neuropeptides (vasopressin, $\mathrm{ACTH}_{4-10}$ ) on avoidance behavior, Physiol. Behav., 22 (1979) 291-295.

31 Van Wimersma Greidanus, Tj. B., Bohus, B. and De Wied, D., Vasopressin and oxytocin in learning and memory. In J. L. Martinez, Jr., R. A. Jensen, R. B. Messing, H. Rigter and J. L. McGaugh (Eds.), Endogenous Peptides and Learning and Memory Processes, Academic Press, New York, 1981, p. 413. 